\title{
The Effects of Choral Repeated Reading on Foreign Language Reading Fluency of Words in Connected and Disconnected Text
}

\author{
Dacian D. Dolean (Corresponding author) \\ Dept. of Educational Sciences, Babes-Bolyai University, Str. Sindicatelor nr. 7, \\ Cluj-Napoca, 400029, Romania
}

Tel: 40-264-405-300Ｅ-mail: dorin.dolean@ubbcluj.ro

Crina I. Damsa

Dept. of Teacher Education and School Research, University of Oslo, Postboks 1099 Blindern0317 OSLO, Norway

Tel: 47-2284-0725Ｅ-mail: crina.damsa@ils.uio.no

\section{Raluca Pop}

Dept. of Didactics of Social Sciences and Humanities, Babes-Bolyai University, Str. Sindicatelor nr. 7, Cluj-Napoca, 400029, Romania

Tel: 40-264 405-337Ｅ-mail: raluca.petrus@ubbcluj.ro

Received: Nov. 3, 2016 Accepted: Nov. 10, $2016 \quad$ Published: April 8, 2017

doi:10.5296/ijl.v9i2.11051ＵRL: https://doi.org/10.5296/ijl.v9i2.11051

\begin{abstract}
Repeated reading has been successfully used to enhance reading fluency in L1, but little is known about how (and to what extent) this strategy impacts reading in foreign language classrooms. Our paper reports the results of a 5-week intervention program aimed to improve reading fluency of middle school students during their English as a foreign language classes. Four classes of sixth-graders divided in two groups received two reading treatments for the last 15 minutes of the class: choral repeated reading (CRR) and reading comprehension/vocabulary development (RC/VD). Results indicated that a short term
\end{abstract}




\section{Macrothink}

International Journal of Linguistics

ISSN 1948-5425

intervention program of repeated reading can lead to significant improvements of fluency only at lexical level (words in disconnected text) but not at syntactic level (words in connected text). Pedagogical implications and further research directions are addressed.

Keywords: Reading fluency, Repeated reading, Choral reading, Foreign language learners, Reading comprehension 


\section{Introduction}

Reading fluency (RF) has been identified as one of the main components of reading proficiency (NRP, 2000). Given that the ultimate goal of reading is to understand what is being read, the growing interest in RF is probably best explained by its moderate to strong correlation with reading comprehension (e.g. Rasinski et al., 2005; Roberts, Doog \& Corcoran, 2005). The relationship has been framed conceptually by the Automaticity Theory (LaBerge \& Samuels, 1974) and Verbal Efficiency Theory (Perfetti, 1985). Both theories suggest that the more automatized the reading fluency, the more cognitive resources (e.g. attention, short-term memory) readers can employ to focus on understanding the meaning of what is being read. Thus, the development of RF plays a crucial role in the process of comprehending the meaning of what is being read. While there are many empirical studies that explored how can native speakers improve their RF skills in the classroom, surprisingly there is little evidence about how this skill can be enhanced during foreign language (FL) classes. Furthermore, it is unclear whether the development of RF in a FL is similar at lexical level (words in disconnected texts) with the one at syntactic level (words in connected text), given different predictive values of the two levels of RF on reading comprehension. In this study we will explore the potential advantage of improving RF in a foreign language (FL) at both lexical and syntactic levels using a strategy that has been reported to be effective in L1 reading classes: choral repeated reading.

\section{Review of Literature}

\subsection{Levels of $R F$}

Learning to read automatically is a multi-step process and readers can become fluent at different levels. For instance, Biemiller (1981) was among the first to indicate that the performance of RF is higher when reading words in a connected text, compared with reading words in disconnected text. More recent studies (e.g. Hudson, Torgesen, Lane \& Turner, 2012) show that there are several levels of RF and that developing readers can perform differently depending on the tasks that they are being given (i.e. rapid automatized letters naming, grapheme-phoneme connections, phonemic blending, decoding non-sense words, decoding words in disconnected and connected text). Jenkins et al. (2003) analyzed the relationships between the levels of RF to reading comprehension and found that RF in connected text is the best predictor for reading comprehension, accounting for $41 \%$ of unique variance above reading fluency of words in disconnected text. The outcome of their research is consistent with other studies that found the ability to read fluently a connected text to account for most of the variance in predicting proficiency in reading comprehension, compared with reading fluently words in disconnected texts in the native language (L1) (e.g. Baker, Stoolmiller, Good \& Baker, 2011; Klauda \& Guthire, 2008) and FL (Crosson \& Lesaux, 2010; Jeon, 2012; Jiang, Sawaki \& Sabatini, 2012).

These findings imply that, when assessing RF, it is important to consider which levels we analyze and what is their relation to reading comprehension (Klauda \& Guthire, 2008). In our study we contrast the growth of RF at lexical (words in disconnected text) and syntactic (words in connected text) level, because the two tasks have different predictive values for 
reading comprehension.

\subsection{Repeated Reading as an Instructional Strategy to Enhance RF}

Repeated reading is a strategy indicated as enhancing for RF, and often used by classroom teachers. This strategy was successfully used to improve RF as shown by measures that included non-words, or words in both disconnected and connected text (Meyer \& Felton, 1999; Therrien, 2004; Therrien \& Kubina, 2006). As an intervention, repeated reading generated positive results when reading activities were conducted with or without a model; however, the strategy appeared to be the most efficient when the teacher models the reading (Chard, Vaughn \& Tyler, 2002; Dolean, Tincas \& Damsa, 2016). Modeling reading can be performed individually (teacher reads aloud and students listen/follow the text silently) or chorally (both teacher and students read aloud simultaneously).

While several studies used individual teacher modeling as an intervention to improve RF, there are a few empirical studies that addressed the impact of the choral repeated reading (CRR) on RF. Empirical evidence on this strategy indicates that it can be used as aan efficient strategy to improve RF (Rasinski, 1989; Rasinski 2003; Samuels, 2006), measured by speed and accuracy of words in disconnected and connected text (Paige, 2011), as well as in speech prosody (Miccinati, 1985). One of the advantages of CRR is that it allows speakers to synchronize fairly quickly, without the need of practice (Cummins, 2003), thus allowing readers to benefit from it from the very first trial. An analysis of the available literature on the topic led to the conclusion that further and more specific empirical evidence is needed on how CRR influences reading fluency in FL classes, and how effective this strategy is in relation with reading comprehension when it is used in FL lessons.

\subsection{Reading Fluency in a FL}

Empirical studies suggest that the development of RF in a FL does not always follow the same path with L1 and that the development of RF at syntactic level is a much slower and tenuous process compared to L1 (see Fraser, 2004). Review studies suggest that decoding skills develop faster than comprehension skills, and consequently, FL learners have significantly larger gaps between scores on RF and reading comprehension measures compared with L1 learners (Quirk \& Beam, 2012; Reschly et al., 2009). The reason why FL learners lag behind their comprehension skills can be explained by the lack of vocabulary skills (Lervåg \& Aukrust, 2009) or syntactic knowledge (Shiotsu \& Weir, 2007). In a meta-analysis Melby-Lervag and Lervag (2014) showed that differences between L1 and FL learners are rather small at word decoding level, because of the higher transfer rate of linguistic skills from L1 to FL. However, those differences are large when FL learners read words in connected texts, suggesting that reading skills decrease substantially at reading comprehension level. The authors also found that FL learners had a moderate to a large disadvantage in reading comprehension, a large disadvantage in linguistic comprehension but no, or only a very small, disadvantage in decoding skills. These studies indicate that reading development of FL learners might increase faster at lexical level compared with syntactic level. But how does this impact the teaching strategies used by FL teachers in order to improve reading in a foreign language? 


\section{MlMacrothink}

International Journal of Linguistics

ISSN 1948-5425

2017, Vol. 9, No. 2

The existing studies in the literature that focused on improving RF in L2/FL classrooms through repeated reading provide mixed results. On one hand, a handful of studies indicate that repeated reading improved fluency and comprehension of FL learners (e.g. Blum et al., 1995; Gorsuch \& Taguchi, 2008), while other studies found little to no positive effect of repeated reading on RF compared with other control reading methods (e.g. Denton, Anthony, Parker \& Hansbrouck, 2004; Taguchi, Takayasu-Maass, \& Gorsuch, 2004).

Our study will address this by comparing the efficiency of this strategy on RF at lexical and syntactical level.

\section{Present Study}

The reviewed literature indicates the scarce empirical evidence existent on improving RF in FL classes. The following study aims to provide empirical evidence on the effects of CRR on FL reading fluency through an intervention program. The study focuses specifically on examining whether (and to what extent) choral repeated reading, used as strategy to improve RF, can improve RF of FL learners. The following research questions are addressed in order to pursue this examination:

1. Does CRR improve RF when reading texts in a FL compared with reading activities focused on comprehension?

2. Does CRR improve RF when reading texts in a FL at both lexical and syntactic level?

\section{Method}

\subsection{Participants}

Eighty eight sixth-grade students (aged 12-13) attending one of four parallel classes of the same urban middle school from Romania were initially considered to be included in our study, which was part of a school project aimed to enhance reading skills in English. All six graders took part in our intervention program because they all attended the participating classes. After we distributed the four classes to one of the two treatments (see Procedures), we controlled the two groups by the English and general academic performance. The final sample of participants that was included in our analysis had 61 students, distributed to either the choral repeated reading ( $n=32,17$ boys) and reading comprehension ( $\mathrm{n}=29,15$ boys) treatment (see Procedures). All participating students attended three hours per week of English classes, and they all started formal English lessons in the $1^{\text {st }}$ grade. None of them came from a socio-economic disadvantaged environment (as reflected by school records), and neither one belonged to a linguistic minority group.

\subsection{Procedures}

The participants were initially tested (Time 1) for RF in English (see Measures section). Then the four classes were paired in dyads (groups), with the mean scores of each dyad not statistically different $(p>.05)$ in RF (see Table 1). The data from school records indicated there was no significant difference $(p>.05)$ between the two groups at the end of previous academic year as reflected by end-of-the year grades and English grades. Next, the two 
groups were distributed randomly (coin toss) to one of the two treatments: choral repeated reading (CRR) and reading comprehension/vocabulary development (RC/VD).

A 5-week long intervention program was started one week after the initial testing. The program was implemented by the regular classroom teachers, who were initially trained to implement each treatment. The teachers taught the (same) subject, following the national curriculum, and used the same textbooks for the first 35 minutes of each class. However, the last 15 minutes, they were instructed to use reading booklets provided by the research team. The booklets consisted in 15 stories ( 3 hours per week x 5 weeks) followed by activities focused on RC/VD. The stories were about 150-180 words long. Each story included 5 to 8 new content words. The booklets were not available for sale in any store, and none of the teachers or students declared they were familiar with them.

The teachers from the two different treatments were instructed to use the booklets in their lessons differently. The teachers from CRR treatment conducted choral group reading activities, focused on developing RF. The activities started with the teacher reading out loud (modeling) the text, and students (with the help of the teacher when necessary) were translating out loud its meaning. Then, the teacher organized CRR activities, when the whole class would engage simultaneously in reading the text for 4 times. The repeated reading strategies varied in speed (the more students read the same text, the higher the speed).

The teachers from RC/VD treatment were instructed to focus their lessons on understanding the meaning of the text and developing the vocabulary skills. They started their intervention similarly with teachers from CRR treatment, by reading out loud (modeling) and translating the text. Then, the teacher focused the class activities on reading comprehension, by developing the vocabulary skills of students using the exercises from the booklets. These activities consisted on exercises of matching (the word with its definition), answering comprehension questions, fill the new words in the blanks, defining them by finding the opposites or breaking down the words by word parts (suffixes and prefixes).

The teachers were instructed to retain the booklets at the end of each class, so that students did not have access to the texts outside the intervention program. After the 5-week intervention program, the students' performance was measured again (Time 2) for RF and RC/VD.

\subsection{Measures}

The assessment of students' progress was conducted using standardized (RF syntactic level) and curriculum-based (RF lexical level) measures.

\section{Reading fluency}

The assessment of RF was conducted at lexical (words in disconnected text) and at syntactical (words in connected text) level. The students were tested by two researchers, in a quiet room within their school. The fluency was measured by the number of correct words read per minute (e.g. Fuchs, Fuchs, Hosp \& Jenkins, 2001). The inter-rater agreement measured at Time 1 indicated a strong correlation for assessments conducted at both lexical ( $r$ 
$=.99)$ and syntactic $(r=.99)$ level. We used the following instruments to measure RF:

Words in disconnected text (lexical level)

In order to select the list of words used for the assessment, the participating children received initially all 2-syllable words $(n=105)$ from Spache's revised words list (Spache, 1974) that any $6^{\text {th }}$ grader from Romania should have been familiar with (e.g. color). Then, the participants were asked to indicate (underline) which words they found unfamiliar (they never saw written before). The percentage of familiarity score was measured by subtracting the sum of frequencies of each word identified unfamiliar by students from 100. The familiarity score of the words ranged from 47.62 to 100 percent. After that, the research team discussed the results with their classroom teachers to identify which words students were less likely to have met. Nine words were taken out of the list, so the total number of words that were included in the assessment instruments was 96. All words had a familiarity average score of more than $90 \%$, as indicated by students' answers. The remaining words were randomly distributed in two groups (48 words each). The research team field tested the correlation between the scores of RF for each list using a separate sample of 10 same-age students. Results showed a strong correlation between the two parallel forms $(r=.95)$, indicating that using the two lists to assess RF was highly reliable. The forms were randomly distributed to either pre-test (Time 1) or post-test (Time 2) assessment session.

\section{Words in connected text (syntactic level)}

The assessment of RF at syntactic level was conducted by using two parallel forms of DIBELS Oral Reading Fluency (Good \& Kaminski, 1982). The forms included short stories of about 200 words. One form was used for pre-test (Time 1) and the other one for post-test (Time 2). Given that the instrument was originally designed for English speakers and not for FL learners, we selected the assessment forms by asking four English teachers to rate ten of them from a scale from 1 (not appropriate) to 4 (very appropriate). The two forms with the highest scores were selected for our assessment. A field test conducted on 10 same-age students showed a strong correlation $(r=.98)$ between the two forms.

\section{Results}

The intervention program indicated that the measures of fluency showed mixed results. Descriptive statistics are displayed in Table 1. 


\section{1) Macrothink}

Table 1. Descriptive statistics of students' performance at RF and RC/VD measures

\begin{tabular}{|c|c|c|c|c|c|}
\hline & & & & & /VD \\
\hline & & $\mathrm{N}=32$ & & $\mathrm{~N}=29$ & \\
\hline & & Time 1 & Time 2 & Time 1 & Time 2 \\
\hline & & $\mathrm{M}(\mathrm{SD})$ & $\mathrm{M}(\mathrm{SD})$ & $\mathrm{M}(\mathrm{SD})$ & $\mathrm{M}(\mathrm{SD})$ \\
\hline RF & Lexical & $73.64(17.23)$ & 86.05 (19.67) & $68.32(21.12)$ & $71.07(20.07)$ \\
\hline & Syntactic & $89.56(22.54)$ & $95.03(30.09)$ & 88.69 (21.69) & $86.69(28.85)$ \\
\hline
\end{tabular}

*Note: $\mathrm{RF}=$ reading fluency; $\mathrm{CRR}=$ choral repeated reading treatment; $\mathrm{RC} / \mathrm{VD}=$ reading comprehension/vocabulary development treatment.

** Note: RF scores represent the number of correct words read per minute.

Four 2 (treatment: CRR vs. RC/VD) $\times 2$ (time: Time 1 vs. Time 2) mixed analyses of variance (ANOVA) were conducted, with RF (lexical, syntactic) and RC/VD, respectively, as dependent variables.

The analysis for RF at lexical level showed significant main effects of time $F(1,59)=40.64$, $p<.001, \eta_{p}{ }^{2}=.408$ (higher scores at Time 2 vs. Time 1 ), treatment $F(1,59)=4.40, p=.040$, $\eta_{p}{ }^{2}=.069$ (higher scores for CRR vs. RC/VD), and a significant interaction effect of time and treatment $F(1,59)=16.48, p<.001, \eta_{p}{ }^{2}=.218$ (the score increase is higher for CRR compared to RC/VD). We found no significant main effect of time $F<1$, treatment, $F<1$, and no significant interaction effect $F(1,59)=2.42, p>.05, \eta_{p}{ }^{2}=.039$ in the case of RF at syntactic level.

\section{Discussion}

This paper aimed to investigate the effects of CRR on reading fluency of FL learners, by clarifying whether CRR improves RF compared with a different reading method, by comparing the effects of CRR on RF at both lexical and syntactic level. The results show that CRR improved RF compared with reading activities focused on comprehension, but that the progress was significant only at decoding (lexical) level, and that the effect size for treatment was small. The results indicate that, possibly a longer intervention program (see Taguchi \& Gorsuch, 2002, but also Taguchi, Takayasu-Maass \& Gorsuch, 2004) could lead to a stronger effect size for treatment. The increase in fluency of students from CRR treatment could be partially explained by the fact that students were not used with this type of activities, 
according to their teachers. Therefore, when they were assessed in Time 1, their performance was lower than their potential because they did not have the prior experience to read aloud fast and accurate. Nevertheless, our results showed that the intervention program helped RF increase significantly only at lexical (and not syntactic) level, supporting the idea that FL learners develop their decoding abilities at a faster rate than their reading comprehension abilities (Melby- Lervåg \& Lervåg, 2014).

Previous studies have shown that during CRR the reader is more focused on synchrony with the partner, rather than to convey meaning from text, because the speech was found to be less variable in choral than in solo reading (Poore \& Ferguson, 2008). However, it is interesting to note that while this phenomenon does not seem to affect L1 readers to enhance RF through CRR at syntactic level (Rasinki, 2003), it might be more detrimental for FL readers. The difference between the RF performance in L1 and FL can be explained by the low vocabulary skills (Lervåg \& Aukrust, 2009), poor syntactic knowledge (Shiotsu \& Weir, 2007), or diminished cognitive resources of FL readers that are necessary to focus on both meaning and the form during CRR (i.e. attentional and short-term memory, see LaBerge \& Samuels, 1974).

Our findings need to be treated with caution due to at least one limitation: Although we have controlled for the components of the two groups for learning disabilities, general (and English) academic performance and home tutoring, it was not possible to control the (more or less) incidental exposure to English outside the school program (e.g. TV, internet, peer influence) and its potential impact on reading skills. A replication of this study in a more controlled environment (e.g. summer camp) that uses a less familiar FL would address this issue.

\section{Conclusion}

The current research shows that CRR can have positive effects on RF performance of FL learners at the lexical level, but that it has a limited effect on fluency at syntactic level. A recommendation for FL teachers is to limit the CRR activities to lesson sequences that focus on decoding enhancement, and not to sequences aimed at improving general reading abilities (and especially reading comprehension).

\section{Acknowledgment}

This work was partially supported by EEA grants / Norway Grants under the program "Research within priority sectors" (15 SEE/30.06.2014).

\section{References}

Baker, D. L., Stoolmiller, M., Good, R. H., \& Baker, S. K. (2011). Effect of reading comprehension on passage fluency in Spanish and English for second-grade English learners. School Psychology Review, 40(3), 331-351.

Biemiller, A. J. (1981). Biemiller test of reading processes. Toronto, Canada: University of Toronto Press.

Blum, I., Koskinen, P. A., Tennant, N., Parker, E. M., Straub, M., \& Curry, C. (1995). Using 
audiotaped books to extend classroom literacy instruction into the homes of second-language learners. Journal of Reading Behavior, 27, 535-563. https://doi.org/10.1080/10862969509547898

Chard, D. J., Vaughn, S., \& Tyler, B. (2002). A synthesis of research on effective interventions for building reading fluency with elementary students with learning disabilities. Journal of Learning Disabilities, 38, 306-406. https://doi.org/https://doi.org/10.1177/00222194020350050101

Crosson, A. C., \& Lesaux, N. K. (2010). Revisiting assumptions about the relationship of fluent reading to comprehension: Spanish-speakers' text-reading fluency in English. Reading and Writing, 23, 475-494. http://dx.doi.org/10.1007/s11145-009-9168-8

Cummins, F. (2003). Practice and performance in speech produced synchronously. Journal of Phonetics, 31(2), 139-148.

Denton, C. A., Anthony, J. L., Parker, R., \& Hansbrouck, J. E. (2004). Effects of two tutoring programs on the English reading development of Spanish-English bilingual students. The Elementary School Journal, 104(4),289-305. https://doi.org/10.1086/499754

Dolean, D. D., Tincas, I. \& Damsa, C. (2016). What factors influence the development of reading fluency of Roma children? The effects of while-class repeated readings and school absenteeism. Studia Universitatis Babes-Bolyai Psychologia-Paedagogia, 61(2), 5-13.

Fraser, C. A. (2004). L'aisance de lecture en matiere de langue seconde. The Canadian Modern Language Review, 61(1), 135-160. https://doi.org/10.1353/cml.2004.0003

Fuchs, L. S., Fuchs, D., Hosp, M. K., \& Jenkins, J. R. (2001). Oral reading fluency as an indicator of reading competence: A theoretical, empirical and historical analysis. Scientific Studies of Reading, 5(3), 239-256. http://dx.doi.org/10.1207/S1532799XSSR0503_3

Good, R. H., \& Kaminski, R. A. (2002). Dynamic indicators of basic early literacy skills $\left(6^{\text {th }}\right.$ ed.) Eugene, OR: Institute for the Development of Educational Achievement.

Gorsuch, G., \& Taguchi, E. (2008). Repeated reading for developing reading fluency and reading comprehension: The case of EFL learners in Vietnam. System, 36(2), 253-278. http://dx.doi.org/10.1016/j.system.2007.09.009

Hudson, R. F., Torgesen, J. K., Lane, H. B., \& Turner, S. J. (2012). Relations among reading skills and sub-skills and text-level reading proficiency in developing readers. Reading and Writing, 25(2), 483-507. https://doi.org/10.1007/s11145-010-9283-6

Jenkins, J. R., Fuchs, L. S., van den Broek, P., Espin, C., \& Deno, S. L. (2003). Sources of Individual Differences in Reading Comprehension and Reading Fluency. Journal of Educational Psychology, 95(4), 719-729. http://dx.doi.org/10.1037/0022-0663.95.4.719

Jeon, E. H. (2012). Oral reading fluency in second language reading. Reading in a Foreign Language, 24(2), 186-208.

Jiang, X., Sawaki, Y., \& Sabatini, J. (2012). Word reading efficiency, text reading fluency 
and reading comprehension among Chinese learners of English. Reading Psychology, 33, 323-349. https://doi.org/10.1080/02702711.2010.526051

Klauda, S. L., \& Guthrie, J. T. (2008). Relationship of three components of reading fluency to reading comprehension. Journal of Educational Psychology, 100(2), 310-321. http://dx.doi.org/10.1037/0022-0663.100.2.310

LaBerge, D., \& Samuels, S. J. (1974). Toward a theory of automatic information processing in reading. Cognitive Psychology, 6, 293-323.

Lervåg, A. O., \& Aukrust, V. G. (2010). Vocabulary knowledge is a critical determinant of the difference in reading comprehension growth between first and second language learners. Journal of Child Psychology and Psychiatry. 51(5), 612- 620. https://doi.org/10.1111/j.1469-7610.2009.02185.x

Melby-Lervåg, M., \& Lervåg, A. (2014). Reading Comprehension and its Underlying Components in Second Language Learners: A Meta-analysis of Studies Comparing First and Second Language Learners. Psychological bulletin, 140(2), 409-433. http://dx.doi.org/10.1037/a0033890

Meyer, M. S., \& Felton, R. H. (1999). Repeated reading to enhance fluency: Old approaches and new directions. Annals of Dyslexia, 49, 283-306. doi:10.1007/s11881-999-0027-8

Miccinati, J. L. (1985). Using prosodic cues to teach oral reading fluency. The Reading Teacher, 39, 206-212.

National Reading Panel (2000). Teaching children to read: An evidence-based assessment of the scientific research literature on reading and its implications for reading instruction. (NIH Publication No. 00-4769) Washington, DC: U.S. Department of Health and Human Services, National Reading Institute of Child Health and Human Development.

Paige, D. D. (2011). 16 Minutes of "Eyes-on-Text" Can Make a Difference: Whole-Class Choral Reading as an Adolescent Fluency Strategy. Reading Horizons, 51(1), 1-20.

Perfetti, C. A. (1985). Reading ability. New York, NY: Oxford University Press.

Poore, M. A. \& Ferguson, S. H. (2008). Methodological variables in choral reading. Clinical Linguistics \& Phonetics, 22(1), 13-24. http://dx.doi.org/10.1080/02699200701601971

Quirk, M. \& Beem, S. (2012). Examining the relations between reading fluency and reading comprehension for English language learners. Psychology in the Schools, 49(6), 539-553. https://doi.org/10.1002/pits.21616

Rasinski, T. V. (1989). Fluency for everyone: Incorporating fluency instruction in the classroom. The Reading Teacher, 42, 690-693.

Rasinski, T. V. (2003). The fluent reader: Oral reading strategies for building word recognition, fluency, and comprehension. New York, New York: Scholastic.

Rasinski, T. V., Padak, N. D., McKeon, C. A., Wilfong, L. G., Friedhauer, J. A., \& Heim, P. 
(2005). Is reading fluency a key for successful high school reading? Journal of Adolescent \& Adult Literacy, 49, 22-27. https://doi.org/https://doi.org/10.1598/JAAL.49.1.3

Reschly, A. L., Busch, T. W., Betts, J., Deno, S. L., \& Long, J. D. (2009). Curriculum-based measurement oral reading as an indicator of reading achievement: a meta-analysis of the correlational evidence. Journal of School Psychology, 47(6), 427-469. https://doi.org/10.1598/JAAL.49.1.3

Roberts, G., Good, R., \& Corcoran, S. (2005). Story retell: A fluency-based indicator of reading comprehension. School Psychology Quarterly, 20(3), 304-317. http://dx.doi.org/10.1521/scpq.2005.20.3.304

Samuels, S. J. (2006). Towards a model of reading fluency. In Samuels, S. J. \& Farstrup, A. E. (Eds.). What research has to say about fluency instruction (pp. 24-46). Newark, DE: International Reading Association.

Shiotsu, T., \& Weir, C. J. (2007). The relative significance of syntactic knowledge and vocabulary breadth in the prediction of reading comprehension test performance. Language Testing, 24(1), 99-128. https://doi.org/https://doi.org/10.1177/0265532207071513

Spache, G. (1974). Good reading for poor readers. Champaign, IL: Garrard.

Taguchi, E., \& Gorsuch, G. (2002). Transfer effects of repeated EFL reading on reading new passages: silent reading rate and comprehension. Reading in a Foreign Language, 14(1), $1-18$.

Taguchi, E., Takayasu-Maass, M., \& Gorsuch, G. J. (2004). Developing reading fluency in EFL: How assisted repeated reading and extensive reading affect fluency development. Reading in a Foreign Language, 16(2), 70-96.

Therrien, W. J. (2004). Fluency and comprehension gains as a result of repeated reading. Remedial and Special Education, 25, 252-261. https://doi.org/https://doi.org/10.1177/07419325040250040801

Therrien, W. J., \& Kubina, R. M. (2006). Developing reading fluency with repeated reading. Intervention in School and Clinic, 41(3), 156-160. https://doi.org/https://doi.org/10.1177/10534512060410030501

\section{Copyrights}

Copyright for this article is retained by the author(s), with first publication rights granted to the journal.

This is an open-access article distributed under the terms and conditions of the Creative Commons Attribution license (http://creativecommons.org/licenses/by/4.0/) 